\title{
Afecções traumáticas em muçuãs (Kinosternon scorpioides) mantidos em cativeiro
}

\section{Claudio Douglas de Oliveira Guimarães ${ }^{1}$, Alanna do Socorro Lima da Silva ${ }^{2}$ Jamile da $^{2}$ Costa Araújo ${ }^{3}$, Maria das Dores Correia Palha ${ }^{4}$}

${ }^{1}$ Pesquisador do Projeto Bio-Fauna

${ }^{2}$ Prof ${ }^{a}$ da Universidade Federal do Oeste do Pará

${ }^{3}$ Pesquisadora da EMBRAPA/Amapá

${ }^{4}$ Prof ${ }^{a}$ da Universidade Federal Rural da Amazônia

*Autor para correspondência, E-mail: jamilejca@yahoo.com.br

\begin{abstract}
RESUMO: Este estudo objetivou identificar a incidência e a localização de afecções traumáticas em espécimes cativos de muçuãs (Kinosternon scorpioides). Foram utilizados 77 muçuãs provenientes do plantel de reprodução do Criadouro Científico do Projeto BioFauna, localizado na Universidade Federal Rural da Amazônia - UFRA, Belém, PA. Dos 77 animais avaliados $55(70 \%)$ apresentaram algum tipo de alteração traumática, sendo $35(56,5 \%)$ lesões identificadas em fêmeas e 27 (43,5\%) em machos com maior ocorrência durante o período reprodutivo. As lesões macroscópicas identificadas distribuíram-se entre partes moles, plastrão e carapaça. Os agentes isolados de abscessos subcutâneos foram: Morganella morganii, Enterobacter cloaceae e Enterococcus faecium. Pode-se concluir que neste estudo a maior frequência de casos de alterações do tegumento em muçuãs coincidiu com o período reprodutivo, e as lesões localizaram-se principalmente nas partes moles.
\end{abstract}

Palavras chave: Patologia, quelônios, dermatologia, biologia.

\section{Traumatic affections in scorpion mud turtle (Kinosternon scorpioides) kept in captivity}

\begin{abstract}
This study aimed to identify the incidence and location of traumatic disorders in captive specimens of scorpion mud turtle (Kinosternon scorpioides). For this, we used 77 animals from the squad to play the Criadouro Científico do Projeto BioFauna, located at the Federal Rural University of Amazonia - UFRA, Belém, PA. Of the 77 animals evaluated $55(70 \%)$ had some kind of traumatic injuries, with $35(56,5 \%)$ lesions identified in females and $27(43,5 \%)$ with higher incidence in males during the breeding period. Lesions identified were distributed among soft tissues, carapace and plastron. The agents were isolated from subcutaneous abscesses: Morganella morganii, Enterobacter cloaceae and Enterococcus faecium. It can be concluded that in this study the highest frequency of cases of changes in the integument mud turtle coincided with the reproductive period, and the lesions were located mainly in the soft tissue.
\end{abstract}

Keywords: Pathology, chelonians, dermatology, biology.

\section{Introdução}

Os répteis, tal como os mamíferos, apresentam a pele composta por células queratinizadas que, embora formem lâminas delgadas dispostas em camadas (epiderme) são flexíveis e altamente resistentes à perda hídrica (Hickman et al., 2004; Junqueira \& Carneiro,
2008; Pough et al., 2008). Associada à epiderme encontra-se uma derme muito espessa e bem desenvolvida, com poucas glândulas anexas. Juntas, constituem barreira protetora que confere maior resistência contra agentes agressores externos (Romer \& Parsons, 1985; Hickman et al., 2004; Pough et al., 2008). 
De acordo com Cooper (2006), patologias de pele são comuns em répteis, especialmente quando mantidos em ambiente cativo. Essas dermatopatias podem ter origem infecciosa (fúngica, bacteriana, viral e parasitária) ou física, sendo as lesões traumáticas as principais apresentações clínicas na medicina de répteis (Frye, 1973; Matushima, 2001).

Em quelônios, as afecções traumáticas ganham destaque, principalmente pelo fato desses animais apresentarem um casco protetor sobre o corpo e que está sujeito a diferentes tipos de injúrias. Este casco é formado por estrutura óssea, originada pela fusão de costelas, vértebras torácicas, lombares e sacrais, bem como alguns ossos da cintura pélvica e torácica. Pode ser dividido em duas porções: a porção convexa dorsal, denominada carapaça, e a parte inferior, geralmente plana ou até mesmo côncava, denominada plastrão. Estas duas seções são unidas por uma ponte estreita de cada lado, que pode ser óssea ou não (Goulart, 2004).

Infecções de carapaça e plastrão também podem estar associadas à morbidade em quelônios cativos, muitas vezes sendo consequência de inapropriadas práticas de manejo (Barnett, 2003). Além disso, lesões resultantes de ferimentos por predadores, dieta inadequada e agressões intraespecíficas são fatores que podem predispor a processos infeciosos de casco (Bernett, 2003; Cubas \& Baptistotte, 2006).

O Kinosternon scorpioides é um pequeno quelônio pertencente à família Kinosternidae, típico de áreas de várzea de alguns países das Américas. No Brasil, pode ser encontrado em ambiente natural nas regiões norte, nordeste e centro-oeste do país, nos estados do Amapá, Roraima, Amazonas, Maranhão, Mato Grosso, Tocantins, Rio Grande do Norte, Pernambuco e Pará, com maior ocorrência do Marajó (Rocha \& Molina, 1987; Cubas \& Baptistotte, 2007).

É um animal com características onívoras, apesar de ser primariamente carnívoro (Pritchard \& Trebbau 1984) se alimentando de uma ampla quantidade de invertebrados e pequenos vertebrados (Vanzolini et al. 1980; CastilloCenteno, 1986; Monje-Nájera \& Moreva-Brenes 1987; Carvalho et al., 2008). Apesar dos poucos registros sobre predadores naturais, os kinosternídeos fazem parte da dieta de vertebrados maiores (Berry \& Iverson, 2011). Dessa forma, o K. scorpioides apresenta grande importância ecológica como presa e predador na cadeia alimentar, auxiliando na manutenção do ambiente natural.

No Brasil, embora a caça seja proibida, o muçuã é tido como iguaria na culinária local, sendo intensa e clandestinamente caçado e consumido por populações ribeirinhas da Amazônia ou comercializado para atender demandas de hotéis e restaurantes finos da região (Bramble et al., 1984; Rocha \& Molina, 1987; Acuña-Mensen, 1994; Carvalho et al., 2000; Delbuque, 2000). Reconhecendo a constante ameaça de extinção, a importância ecológica e econômica para a região e a insuficiência de dados bibliográficos sobre esta espécie, principalmente no que discerne aos aspectos clínicos, este trabalho teve como objetivos identificar a incidência e a distribuição anatômica de afecções traumáticas em espécimes cativos de $K$. scorpioides, bem como identificar agentes bacterianos envolvidos nesses processos.

\section{Material e Métodos}

O estudo foi realizado durante 15 meses (abril de 2009 a junho de 2010), e consistiu nas análises de casos clínicos durante as avaliações mensais de espécimes de muçuãs (Kinosternon scorpioides) pertencentes ao Criadouro Científico de Animais Silvestres do Projeto Bio-Fauna, Instituto Socioambiental e dos Recursos Hídricos, localizado no campus sede da Universidade Federal Rural da Amazônia UFRA, em Belém, Pará, legalizado junto ao IBAMA (Instituto Brasileiro do Meio Ambiente e dos Recursos Naturais Renováveis) mediante licença $\mathrm{n}^{\circ} 1602685$.

Os animais utilizados no estudo compunham o plantel de reprodução do Criadouro $(n=77)$. Os quais eram distribuídos em cinco recintos obedecendo a proporção macho e fêmea de 1:3. Os recintos foram construídos em alvenaria medindo $5 \mathrm{~m} \times 2,18 \mathrm{~m} \times 1,5 \mathrm{~m}$, respectivamente para comprimento, largura e profundidade, com $75 \%$ do volume correspondendo ao espelho d'água. Uma rampa em alvenaria favoreceu o acesso dos animais à parte seca do recinto com substrato de areia lavada, correspondendo a $25 \%$ da área.

Todos os animais foram submetidos a exames clínicos mensais, com registro dos dados em fichas específicas. Adicionalmente, realizaram-se inspeções diárias do lote para observação dos animais, inclusive registros comportamentais em 
caráter assistemático, além dos procedimentos semanais para a limpeza e manutenção de recintos e do plantel, conforme rotina do Criadouro. Espécimes que apresentaram abscessos não fistulados foram avaliados mais detalhadamente, sendo coletado material para exames microbiológicos, realizados em laboratório particular mediante parceria interinstitucional.

Os dados referentes aos achados clínicos foram registrados e processados por meio do programa computacional Excel, empregando-se estatística descritiva simples.

\section{Resultados e Discussão}

Durante o estudo clínico, dos 77 animais pertencentes ao plantel de reprodução, $70 \%$ apresentaram algum tipo de alteração dermatológica ou afecção de carapaça e/ou plastrão, cuja extensão e localização foram variáveis.

Nesta pesquisa, foram identificadas 62 lesões das quais $43,5 \%(n=27)$ ocorreram em machos de muçuãs e $56,5 \% \quad(n=35)$ em fêmeas, sendo observadas na carapaça, no plastrão e nas partes moles (cabeça, cauda e membros) (Tabela 1).

Tabela 1. Distribuição das afecções de acordo com a localização anatômica e o gênero dos animais. V.A.=Valor absoluto.

\begin{tabular}{|c|c|c|c|c|}
\hline \multirow{2}{*}{ Localização } & \multicolumn{2}{|r|}{ q } & \multicolumn{2}{|r|}{$\hat{\sigma}$} \\
\hline & V.A. & $\%$ & V.A. & $\%$ \\
\hline Partes moles & 21 & $60 \%$ & 22 & $81 \%$ \\
\hline Carapaça & 1 & $3 \%$ & 2 & $7 \%$ \\
\hline Plastrão & 13 & $37 \%$ & 3 & $11 \%$ \\
\hline Total & 35 & $100 \%$ & 27 & $100 \%$ \\
\hline
\end{tabular}

Verificou-se que o período de maior ocorrência das afecções coincidiu com a estação reprodutiva de 2009 (entre abril e outubro) e a estação reprodutiva de 2010, iniciada no final de janeiro e vigente até o final do estudo (Figura 1). Esses achados indicam que muçuãs apresentam comportamentos agressivos especialmente em épocas de procriação, fato também observado para Phrynops geoffroanus (Molina, 1992a) e descrito como etologicamente normal conforme Goulart (2004).

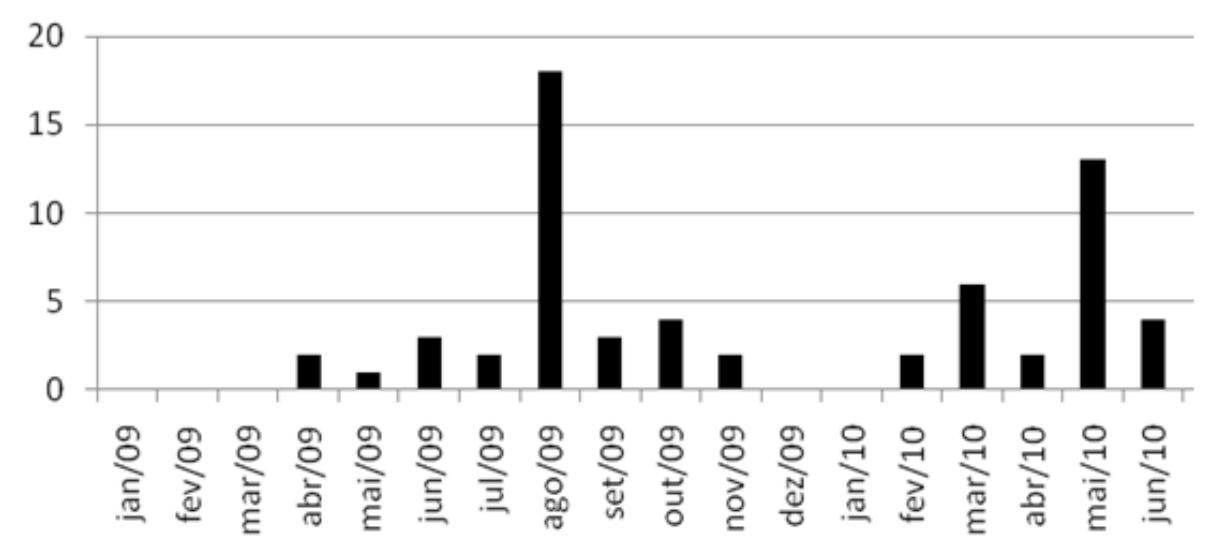

Figura 1: Distribuição mensal das ocorrências de afecções traumáticas em Kinosternon scorpioides de abril de 2009 a junho de 2010.

Molina (1992b) relata que interações agressivas podem envolver indivíduos de qualquer sexo sendo, entretanto, mais frequentes entre machos adultos, especialmente durante a época reprodutiva. Segundo Mahmoud (1967), o encontro entre dois machos de Kinosternídeos termina com a indiferença entre ambos, resultando frequentemente em agressões. Para espécimes de $P$. geoffroanus o agressor persegue e tenta morder principalmente a cauda e região posterior do casco do agredido, que se limita a fugir, direcionando sua carapaça ao agressor, à maneira de um escudo. Durante a fuga o indivíduo agredido não nada em linha reta, mas 
em rotas semicirculares, podendo até abandonar a água. As perseguições são normalmente de curta duração e o agressor pode ser maior ou menor que o agredido. Comportamento semelhante foi observado neste estudo, onde machos agredidos não apresentavam uma trajetória retilínea ao nadar, geralmente locomovendo-se de forma tangencial à lateral do tanque, saindo da água posteriormente.

Das 22 lesões distribuídas entre as partes moles de machos de muçuãs, 68,2\% $(n=15)$ incidiram sobre a região da cauda, $13,6 \%(n=3)$ sobre os membros, $13,6 \%(n=3)$ sobre a região da cabeça e pescoço e 9,1\% (n=1) sobre demais regiões dermatológicas (região inguinal). De acordo com Avanzi \& Millefanti (2004), podem ser observadas lesões pericloacais, às vezes muito profundas, com abundância de tecido necrótico, tumefações e secreções na margem da cloaca, na região da cauda, tal como observado neste estudo. Foram identificadas cinco lesões nas partes ósseas, das quais $80 \%(\mathrm{n}=4)$ acometeram placas ósseas do plastrão e $20 \%(\mathrm{n}=1)$ incidiram sobre as placas da carapaça de espécimes do gênero masculinos.

Para fêmeas de muçuãs, as regiões de cabeça e pescoço foram as mais afetadas, correspondendo a 40,9\% (n=9) das 21 alterações identificadas em regiões desprovidas de proteção óssea. Os membros, a cauda e outras regiões dermatológicas (região inguinal e axilar) corresponderam a $33,3 \%(n=7) ; 14,3 \%(n=3)$ e $9,5 \%(\mathrm{n}=2)$, respectivamente. Em relação à estrutura óssea de fêmeas, foram identificadas 13 lesões, das quais $92,3 \%(\mathrm{n}=12)$ distribuíram-se entre placas ósseas do plastrão e 7,7\% (n=1) entre as placas da carapaça.

A grande concentração das lesões na região de cabeça e pescoço em fêmeas está relacionada ao comportamento de monta da espécie, uma vez que durante a fase de pré-cópula, os machos de algumas espécies de quelônios podem morder a cabeça e o pescoço das fêmeas na tentativa de estimular a parceira (Molina, 1992b). Carpenter (1980) e Novelli \& Sousa (2007) também observaram que machos de cágados mordiam a região do pescoço e dos membros posteriores de fêmeas e machos como estímulos táteis. Comportamento semelhante foi observado durante o acasalamento de muçuãs utilizados neste estudo, em que fêmeas permaneceram sob os machos com estes realizando movimentos pendulares com a cabeça, margeando as bordas da carapaça e mordiscando a região dorsal do pescoço da companheira (Figura 2).

Embora esses achados tenham ocorrido em espécimes cativos, lesões com etiologia semelhante podem ocorrer em indivíduos de vida livre, uma vez que, de acordo com Molina (1989, 1996, 1998), o comportamento reprodutivo (corte, acasalamento e nidificação) de quelônios parece ser estereotipado e, portanto, observações em cativeiro podem refletir o que acontece na natureza.

Neste trabalho foi identificada a formação de nove abscessos subcutâneos em fêmeas de muçuãs (Figura 3), localizados na cabeça e/ou pescoço. Segundo Elkan \& Cooper (1976), os abscessos são lesões que usualmente apresentamse como áreas sobressalentes, endurecidas e edematosas, tipicamente circunscritas. Neste estudo, os abscessos subcutâneos foram facilmente diagnosticados durante a inspeção clínica pelo fato de se apresentarem como nodulações visíveis e consistência firme à palpação. Tais características ao corte estavam de acordo com a descrição de Mader (2006). Este autor afirma que a apresentação típica de um abscesso é lamelar, semelhante em aparência a um corte transversal de uma cebola e em sua maioria apresentam-se como uma massa amarelada sólida, podendo também estar encapsulado, características encontradas em todos os casos.

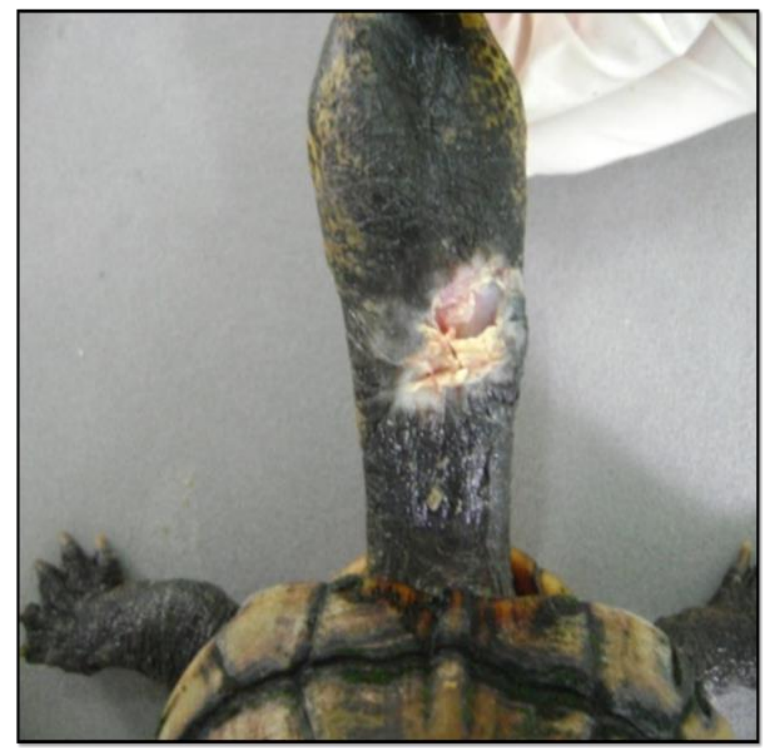

Figura 2: Fêmea de muçuã apresentando lesão no dorso do pescoço, em processo de cicatrização. 


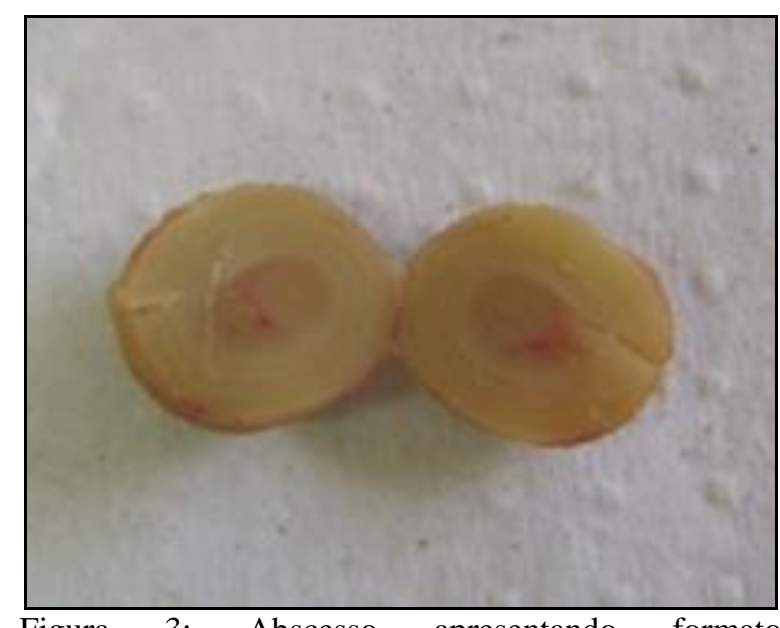

Figura 3: Abscesso apresentando formato arredondado, aspecto caseoso, lamelar, coloração amarelada, consistência firme, semelhante a uma cebola ao corte.

A formação de abscessos nas fêmeas pode estar relacionada ao comportamento reprodutivo, resultado de mordeduras que são usadas como estímulo à parceira (Mo,lina, 1992b). Essas áreas lesionadas podem ter funcionado como porta de entrada para microrganismos piogênicos presentes no ambiente, concorrendo para a formação de abscessos devido à infecção bacteriana pós-trauma (Cooper, 2006). Melo et al. (2008) alertam que além da falta de higiene nos terrários e aquários, a desnutrição também promove queda da resistência orgânica em quelônios cativos, principalmente em animais jovens, propiciando o aparecimento de infecções bacterianas. Fato que também pode estar associado às formações abscedantes encontradas nos animais.

Segundo Grego (2001) as doenças infecciosas são causadas quase sempre devido à imunossupressão, e estas muitas vezes estão associadas com o estresse do cativeiro e acomodações inadequadas. Para Frye (1991), as doenças mais comuns em répteis causadas por bactérias são piogranulomas, pneumonias, dermatites, estomatites e abcessos, verificando-se que bacterías gram-negativas, tais como Pseudomonas aeruginosa e Staphylococcus são mais comumente relatadas como agentes patogênicos, ao passo que doenças associadas com bactérias gram-positivas são esporádicas (Rosenthal \& Mader, 1996).

No presente estudo, foi realizado exame microbiológico em quatro amostras de abscessos, onde foram identificados três agentes microbianos: Morganella morganii (duas amostras), Enterobacter cloaceae (uma amostra) e Enterococcus faecium (uma amostra). Este último microrganismo foi isolado por Ferreira et al. (2012), quando relataram um caso de abscesso subcutâneo em jibóia (Boa constrictor) associado à infecção por M. morganii. Em outro estudo, Jacobson (2007) associou os sinais clínicos correspondentes ao aumento de volume subcutâneo e consistência firme de répteis à formação de abscesso e também encontrou $M$. morganii como bactéria colonizadora.

Frye (1991) e Rossi (1996) realizaram estudos microbiológicos onde foram isoladas várias bactérias gram-negativas envolvidas em lesões de carapaça e plastrão de quelônios, grande parte pertencente à família Enterobacteriaceae. Neste estudo, Enterobacter cloaceae (uma amostra) e Enterococcus faecium (uma amostra), duas espécies de enterobactérias foram identificadas a partir de amostras de abscessos, provavelmente colonizando as lesões, gerando infecção bacteriana secundária.

Não foram realizados exames microbiológicos de lesões de carapaça e plastrão, entretanto, há grande possibilidade dessas áreas estarem colonizadas por fungos e/ou bactérias, como relatado por Hernandez-Divers et al. (2009). Segundo estes autores pequenos conglomerados filamentosos unicelulares e multicelulares fúngicos foram observados em lesões de casco, em espécimes de Graptemys spp. Os mesmos autores supõem que é mais provável que áreas do casco danificadas sejam colonizadas por bactérias, fungos, algas e outros detritos que áreas saudáveis pelo fato destas superfícies apresentarem pouca aderência. Em estudos anteriores, uma variedade de organismos fúngicos, tais como Geotrichum sp, Penicillium $s p$, sp Scolecobasidium, Fusarium sp, Drechslera $s p$, e outros fungos não identificados foram cultivados em lesões superficiais de quelônios (Wiles \& Rand, 1987; Sison et al., 1990).

\section{Conclusões}

Neste estudo a maior frequência de casos de lesões traumáticas coincidiu com o período reprodutivo e as alterações localizaram-se principalmente nas partes moles, seguidas de plastrão e carapaça, tanto em machos quanto em fêmeas de Kinosternon scorpioides. A distribuição anatômica das alterações foi diferente entre os sexos, com as alterações de partes moles apresentando maior frequência na 
região da cabeça e pescoço entre as fêmeas, enquanto que para machos, a região da cauda foi a mais acometida. Em ambos os sexos as lesões foram resultantes principalmente de traumas devido ao comportamento reprodutivo da espécie ou disputas intraespecíficas por parceiras. Visto que as agressões são mais frequentes durante a época reprodutiva, sugere-se que durante esse período, as avaliações clínicas do plantel sejam mais intensificadas a fim de que lesões brandas sejam precocemente tratadas evitando futuras complicações sistêmicas. Além disso, é possível que um manejo reprodutivo diferenciado nesta fase minimize a ocorrência de lesões, mas isso permanece a ser discutido e validado.

\section{Agradecimentos}

À equipe de pesquisadores e demais membros do GP-Bio-Fauna. Ao Conselho Nacional de Desenvolvimento Científico e Tecnológico (CNPq) pela concessão da bolsa de iniciação científica.

\section{Referências Bibliográficas}

Acuña-Mensen, R.A. 1994. Morphomeric variation and ecological characteristics of the habitat of the Scorpion Mud Turtle Kinosternon scorpioides in Costa Rica (Chelonia, Kinosternidae). Revista Brasileira de Biologia, 4(3):537-547.

Avanzi M. \& Millefanti M. 2004. Salud y enfermidades, p.114-131. In: Avanzi M.; Millefanti M. (Eds), El Gran Libro de las Tortugas. Balmes, Barcelona. 219p.

Barnett S. 2003. Shell infections: when there are chinks in the armor. Newsletter of the MidAtlantic Turtles \& Tortoise Society: Terrapin Tales (MATTS). October: 1-8.

Berry, J.F. \& Iverson, J.B. 2011. Kinosternon scorpioides (Linnaeus 1766) - Scorpion Mud Turtle. In: Rhodin, A.G.J., Pritchard, P.C.H., Van Dijk, P.P.; Saumure, R.A.; Buhlmann, K.A.; Iverson, J.B. \& Mittermeier, R.A. (Eds.). Conservation Biology of Freshwater Turtles and Tortoises: A compilation Project of the IUCN/SSC Tortoise and Freshwater Turtle Specialist Group. Chelonian Research Monographs, 5(1),063.1-063.15.

Bramble, D.M.; Hutchison, J.H. \& Leagler, J.M. 1984. Kinosternid shell kineses: Structure, function and evolution. Copeia, 2, 456- 475.
Carpenter, C.C. 1980. An ethological approach to reproductive success in reptiles. In: Murphy, J. B.; Collins, J. T. (eds). Reproductive, Biology and Diseases of Captive Reptiles. Society Studies Amphibia and Reptilia, Kansas (Contributions to Herpetology, n. 1), p. 33-48.

Carvalho, E.A.R.; Carvalho-Neto, C.; Paschoalini, E.L. 2008. Diet of Kinosternon scorpioides in Serra dos Carajas, eastern Amazonia. Herpetological Review v.39, p. $283-285$.

Carvalho, R.C., Sousa, A.L., Silva, A.L.A., Pereira, J.G., Santos, D.M.S., Pereira, P.D.J. \& Anceles, F.K.L. 2000. Anatomia da traquéia e pulmão do muçuã (Kinosternon scorpioides). Brazilian Journal of the Morphology Science, 17(1), 165-166.

Castillo-Centeno, O. 1986. Factores ecológicos y de Mercado de la reproducción de Rhinoclemmys pulcherrima y Kinosternon scorpioides (Testudines: Emydidae y Kinosternididae) em Costa Rica. Licenciada em biologia com especialidad en zoologia, Ciudad Universitaria "Rodrigo Facio", San José, Costa Rica, 160p.

Cooper, J. E. 2006. Dermatology. In: Mader, D. R. Reptile, Medicine and Surgery. 2. ed. Florida: Marathon, p. 196-215.

Cubas, P.H. \& Baptistotte, C. Chelonia (Tartarugas, Cágado, Jabuti). In: Cubas, Z. S.; Silva, J. C. R.; Catão-Dias, J. L. Tratado de animais selvagens - Medicina Veterinária. São Paulo: Roca, 2006. 1376p. p. 86-119.

Delbuque, M. 2000. Ficha do bicho: muçuã. Globo Rural, n.176, p. 83-84.

Elkan, E. \& Cooper J. E. 1976. Tumours and pseudotumours in some reptiles. Journal of Comparative Pathology, 86, 337-348.

Ferreira, P.R.B.; Oliveira, A.V.D.; Laborda, S.S.; Freire JR, L.J.S.; Queiroz, L.D.T. \& Anunciação, A.V.M. 2012. Infecção por Morganella morganii como causa de abscesso subcutâneo em Boa constrictor em conservação ex situ. Jornal Brasileiro de Ciência Animal, 5(9), 320-334.

Frye, F. L. 1973. Medicine \& Surgery in Captive Reptiles. Bonner Springs. VM Publishing: Inc. 140p. 
Frye, F.L. Reptile Care, an atlas of diseases and treatments. T.F.H. Publications, Inc., Neptune City, New Jersey, Volume I, II, 1991.

Goulart, C. E. S. 2004. Herpetologia, Herpetocultura e Medicina de Répteis. Rio de Janeiro: LF Livros, $1^{a}$ ed. 329p.

Grego, K.F. 2001. Ophidia - restraint, anesthesia, medicine. In: Fowler, M.E. Biology, Medicine and Surgery of South American Wild Animals. Iowa State University Press, p.43-50.

Hernandez-Divers, S.; Hensel, P.; Gladden, J.; Hernandez-Divers, S. M.; Buhmann, K. A.; Sanchez, S.; Latimer, K. S.; Ard, M. \& Camus, A.C. 2009. Investigation of shell disease in map turtles (Graptemys spp.). Journal of Wildlife Diseases, 45, 637-652.

Hickman, C.P.; Roberts, L.S.; Larson, A. Princípios Integrados de Zoologia 11ed. Rio de Janeiro: Editora Guanabara Koogan, 2004. $846 \mathrm{p}$.

Jacobson, E.R. Infectious diseases and pathology of reptiles: Color atlas and text: 1.ed. Boca Raton: CRC Press, 736p, 2007.

Junqueira, L.U.; Carneiro, J. Histologia Básica $11^{\text {a }}$ Edição 2008. Rio de Janeiro: Editora Guanabara Koogan, 2008. 524p.

Mader, D. R. 2006. Reptile Medicine and Surgery. 2. ed. Florida: Marathon, p. $715-$ 721.

Mahmound, I.Y. 1967. Courtship behavior and sexual maturity in four species of Kinosternid turtles. Copeia, n.2, jun. 5, p. 314-319.

Matushima, E. R. 2001. Chelonian infectious diseases and general medicine. In: Fowler, M.E.; Cubas, Z.S. (Eds). Biology, Medicine and Surgery of South American Wild Animals. $1^{\circ}$ Ed. South State Avenue, Ames, Iowa, p. $22-24$.

Melo, C. B.; Falcão, G.R. \& Lemos, J.P. 2008. Ocorrência de bactérias Pseudomonas aeruginosa em filhotes de tartaruga marinha Lepdochelys olivacea em cativeiro. Biologia Geral e Experimental, São Cristóvão, SE, v.8, n.2, p.16-17.

Molina, F. B. 1989. Observações sobre a biologia e o comportamento de Phrynops geoffroanus (Schweigger, 1812) em cativeiro (Reptilia, Testudines, Chelidae). Dissertação de Mestrado. Universidade de São Paulo, Brasil, 185p.
Molina, F.B. 1992a. Observações sobre o comportamento agonístico de cágados Phrynops geoffroanus (Schweigger, 1812) (Reptilia, Testudines, Chelidae) em cativeiro. Biotemas, 5, $79-84$.

Molina, F. B. 1992b. O comportamento reprodutivo de quelônios. Biotemas, v.5, n.2, p.61- 70 .

Molina, F. B. 1996. Mating behavior of captive Geoffroy's side-necked turtles, Phrynops geoffroanus (Testudines: Chelidae). Herpetological Natural History, v.4, p.155 160.

Molina, F. B. 1998. Comportamento e biologia reprodutiva dos cágados Phrynops geoffroanus, Acanthochelys radiolata e Acanthochelys spixii (Testudines, Chelidae) em cativeiro. Revista de Etologia (n. esp.), p. 25-40.

Monge-Nájera, J. \& Moreva-Brenes, B. 1987. Notes on the feeding behavior of a juvenile mud turtle, Kinosternon scorpioides. Herpetological Revew, n.18, p.7-9.

Novelli, I.A. \& Souza, B.M. 2007. Análise descritiva do comportamento de corte e cópula de Hydromedusa maximiliani (Mikan, 1820) (Testudines, Chelidae) em laboratório. Revista Brasileira de Zoociências, v. 9, n. 1, p. 49-56.

Pough, F.H.; Heiser, J. B. \& Janis, C.M. A vida dos vertebrados. $4^{\mathrm{a}}$ Ed.. São Paulo: Editora Atheneu, 2008. $750 \mathrm{p}$.

Pritchard, P.C.H \& Trebbau, P. 1984. The Turtles of Venezuela. Ithaca, New York: Society for the Study of Amphibians and Reptiles, Contributions in Herpetology. 414p.

Rocha, M.B. \& Molina, F.B. 1987. Algumas observações sobre a biologia e manejo do muçuã. Aquacultura, v.2, p.25-26.

Romer, A.S. \& Parsons, T.S. Anatomia comparada dos vertebrados. São Paulo: Atheneu Editora, 1985. 559 p.

Rosenthal, K. L. \& Mader, D.R. Microbiology. In: Reptile medicine and surgery, D. R. Mader (ed.). W. B. Saunders Co., Philadelphia, Pennsylvania, 1996, p. 117-125.

Rossi, J.V. Dermatology. In: Reptile medicine and surgery, D. R. Mader (ed.). W. B. Saunders Co., Philadelphia, Pennsylvania, 1996, cap. 10, p. 104-116. 
Sison, T. M., Padilla, M.A., Vizmanos, M.Z. \& Follosco, M. 1990. Isolation and identification of fungi found in necrotic skin lesions of captive marine turtles (Eretmochelys imbricata). Philippine Journal of Veterinary Medicine, 27, 35-36.

Vanzolini, P.E., Ramos-Costa, A.M.M \& Vitt, L.J. 1980. Répteis das Caatingas. Rio de Janeiro: Academia Brasileira de Ciências. 161 p.

Wiles, M. \& Rand, T.G. 1987. Integumental ulcerative disease in a loggerhead turtle
Caretta caretta at the Bermuda Aquarium: Microbiology and histopathology. Diseases of Aquatic Organisms, 3, 85-90.

Recebido em Dezembro 4, 2014. Aceito Maio 27, 2015

License information: This is an open-access article distributed under the terms of the Creative Commons Attribution License, which permits unrestricted use, distribution, and reproduction in any medium, provided the original work is properly cited. 